\title{
Expert System Diagnoses Damage to Injection Motorcycles with the Certainty Factor Method
}

\author{
Feryanto Ginting ${ }^{1}$, Penda Sudarto Hasugian ${ }^{2}$ \\ ${ }^{1.2}$ Informatics Engineering Program, STMIK Pelita Nusantara, Jl. Iskandar Muda No. 1 \\ Medan, North Sumatra, Indonesia 20154 \\ E-mail: Fery.73ginting@gmail.com,penda.hasugian@gmail.com
}

\begin{abstract}
Motorcycles are the main means of transportation that is widely used to support the activities of their societies. Prior to the development of technology, motorcycles still use carburetors. But motorcycles are still using carburetor system is still quite wasteful. With the development of technology, there is now applying the Yamaha brand motorcycles capable of supplying petrol injection engine needs. Motorcycles injection technology is much more efficient compared to motorcycle carburetor technology, in addition to economical motorcycle of this type has a performance engine and a reliable power. But frequent obstacles that cause damage to the injection Yamaha motorcycle, disrupting users. An expert system is a system that adopts the expertise of an expert an expert in a particular field into the system or a computer program is presented with a display that can be used by a user who is not an expert so that system users can make a decision or set policy like an expert in finishing problem. Certainty factor method used to obtain the value of the certainty of damage from an expert motorcycle injection, so that the user also gets the value of the damage certainty selected symptoms of the experience of experts. The results of diagnostics in expert system that has been made that if the user mencheklis symptoms such as clogged when rotated gas engine, electric distater difficult / lift, lights up when the engine is difficult to use the kick starter, often emit exhaust sound of an explosion, it can be concluded from the analysis that the damage found on the spark plug with a value of $M B=0.99, M D=0: 22$ and Certainty Factor value of $76.66 \%$. The diagnosis ever made by a visitor or mechanical accessible again by entering an email to the database.
\end{abstract}

Keywords: Motorcycles, expert systems, Cetainty Factor.

\section{Introduction}

In an era of fast-paced, many people started looking for ways that can support their activities. Not hanyasmartphone and laptopsaja, but also the vehicle. Today most of the people prefer motorcycles as the main means of transportation compared to other vehicles such as private cars or public transport, as well as being effective and more efficient, [1] Prior to the development of technology, motorcycles still use carburetors, which is a device that mixes air and fuel for an internal combustion engine. But motorcycles are still using carburetor system is still quite wasteful. With the development of technology, there is now applying the Yamaha brand motorcycles capable of supplying petrol injection engine needs. You do this by spraying the fuel that has been measured: by sensors in it that makes motorcycle injection technology is much more efficient compared to motorcycle carburetor technology, in addition to economical motorcycle of this type has a performance engine and a reliable power. [2] But frequent obstacles that cause damage to the injection Yamaha motorcycle, disrupting users. There are still many users do not know the Yamaha motorcycle constraints Yamaha motorcycle damage to the injection-system. The problem for users of Yamaha motorcycles applying the injection can be fatal if not repaired the damage type. In general, users will tend to leave at a mechanical workshop. The level of mechanical difficulties experienced in knowing or determining the type of damage to the brand Yamaha motorcycle injection has prompted researchers to use information technology through a method that combines the expertise and knowledge of an expert to devise a system to solve the problem. Expert systems try to find a satisfactory solution as did an expert. [3] certainty Factoris a measure of certainty to a fact or rule. Certainty Factor provides a draft Measure of Believe (MB) is the belief hypothesis is affected by symptoms and Measure of Disbelieve (MD) is the lack of hypotheses that are affected by the symptoms. This method was chosen because it can display the value of the percentage of confidence in the fact that identified, but it is also this method in a two count only be able to process the data only so that its accuracy is maintained. [4]

\section{Theory}

\subsection{Expert system}


An expert system is a system that adopts the expertise of an expert an expert in a particular field into the system or a computer program is presented with a display that can be used by a user who is not an expert sehinnga with the system user can make a decision or set policy like an expert in finishing problem. [5]

\section{a. Expert System Components}

Expert systems generally have three elements: knowledge base (Knowledge Base), Inference Engine (Inference Engine), and User Interface (UI). [6]

\section{2 certainty Factor}

certainty factor $(\mathrm{CF})$ is a clinical parameter values yangdiberikanMYCIN to show how much confidence. In the face of a problem often found answers that do not have full certainty. Uncertainty of bias in the form of probability or dependent on the outcome of an event.[7]

a. Advantages and Disadvantages MetodeCertainty Factor.

Excess certainty factor method is:

a) This method is suitable for use in an expert system that contains uncertainties.

b) In one calculation process can only handle 2 data only so that the accuracy of the data can be maintained. While the lack of certainty factor method is:

a) Modeling uncertainty using certainty factor calculation method is usually still debated.

b) For more than two pieces of data, should be done several times a data processing. [8]

\subsection{Certainty Factor (Certainty Factor)}

The basic formula kepastian.CF factor $(h, e)=M B(h, e)-M D(h, e)$

Information :

$\mathrm{CF}(\mathrm{h}, \mathrm{e})$ : certainty factor of the hypothesis $\mathrm{h}$ that are affected by symptoms (evidence) e. CF value ranging from -1 to 1 . A value of -1 indicates absolute disbelief while the absolute value of 1 indicates kerpercayaan.

MB (h, e): the size of the increase in confidence (measure of Increased belief) of the hypothesis $h$ that are affected by the symptoms e.

MD (h, e): the size of the increase in distrust (measure of increaseddisbelief) of the hypothesis $h$ that are affected by the symptoms e.

h $\quad:$ Hypothesis (between 0 and 1 ).

e : : Events / facts (evidence).

In one case there will be more than one size of the increase in trust in accordance with many of the symptoms that are owned by hypothesis, so the formula MB and MD as follows:

$$
\begin{aligned}
M B\left[h, e_{1} \otimes e_{2}\right] & \otimes \\
& \stackrel{\otimes}{\otimes} M B\left[h, e_{1}\right] \otimes M B\left[h, e_{2}\right] .\left(1 \otimes M B\left[h, e_{1}\right]\right) \text { Lainnya } \\
M D\left[h, e_{1} \otimes e_{2}\right] \otimes & \stackrel{\otimes}{\otimes} M D\left[h, e_{1}\right] \otimes M D\left[h, e_{2}\right] .\left(1 \otimes M D\left[h, e_{1}\right]\right) \text { Lainnya }
\end{aligned}
$$

\section{Research methods}

This method describes what methods will be used in the study, it is the method of Certanty Factor. certainty factor a calculation degree of certainty to the conclusions obtained were calculated based on the probability.To assist in the preparation of this study, the need for the composition of the framework (Frame Work) is clear in its phases. This framework is the steps that will be done to solve the problem to be discussed. Here is a framework of research:

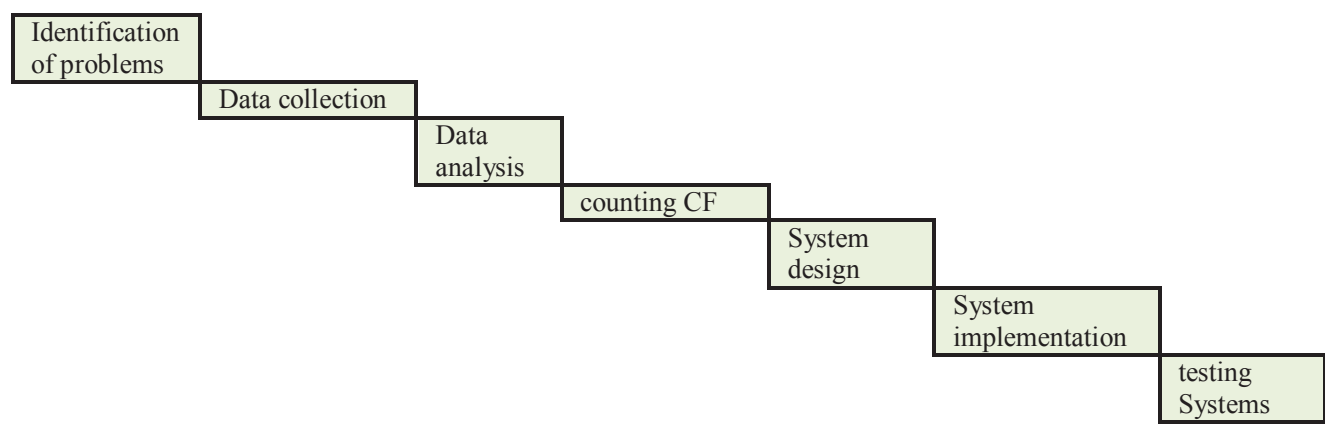

Fig. 1. Flow Research Stages 


\section{Analisia And Design}

\subsection{Data analysis}

The data analysis is the effort or how to process data into information so that the characteristics of the data can be understood and useful for solutions to problems will be resolved, especially issues related to research. The success of an expert system lies in how to cultivate the knowledge derived from data processing to be drawn to a conclusion. Data on the knowledge gained from the research conducted on a motorcycle mechanic injection particularly for Yamaha in the garage Yamaha. From the results of research that has been done, the data obtained from Yamaha motorcycle shop such as the following:

\section{Table 1.}

symPtom

\begin{tabular}{ll} 
Code & \\
\hline KG01 & Engine faltered when played gases. \\
KG02 & Distater electrically difficult / not raised. \\
KG03 & Engineering difficult light up when using the kick starter. \\
KG04 & The road feels stilted. \\
KG05 & Often emit exhaust sound of an explosion. \\
KG06 & Total dead engine. \\
KG07 & Wasteful fuel consumption. \\
KG08 & In the state of the roads was accompanied popping sounds of \\
KG09 & A voreching skid. \\
KG10 & When the engine suddenly died. \\
KG11 & Roads clogged when speeds above 50 km. \\
KG12 & Crackling sound when the road inside the box CVT. \\
KG13 & The machine is turned difficult. \\
KG14 & Less than the maximum traction motors. \\
KG15 & When the handle is opened happen buffeting gas coarse / motorcycle \\
KG16 & Sound rough when the road slowly. \\
KG17 & A decrease in engine performance. \\
KG18 & Exit pungent smell of smoke from the exhaust. \\
KG19 & When exit mengebul dense smoke. \\
KG20 & Acceleration lap top as restrained. \\
KG21 & Engine running at idle is not stable. \\
KG22 & Exit thick white smoke from the exhaust. \\
KG23 & There was the sound of scraping on the machine. \\
KG24 & The engine is very hot. \\
KG25 & Rough engine sound. \\
KG26 & Engine oil quickly reduced. \\
KG27 & Engine oil seeps. \\
\hline &
\end{tabular}

\subsection{Case study}

A motorcycle owners want to know the damage that occurs in its motorcycle injection. Motorcycle experience symptoms such asThe road feels sluggish at best, wasteful fuel consumption, When the engine suddenly died, turned hard Machines, currently unstable engine running idle, engine oil quickly reduced. Here is the calculation of the damage diagnosis manual injection Yamaha motorcycle using Certainty Factor.

$\begin{array}{llll}{[\text { KG04] }} & \text { The road feels stilted. } & \text { MB }[0,8] & \text { MD [0:04] } \\ {[\text { KG07] }} & \text { Wasteful fuel consumption. } & \text { MB [0,2] } & \text { MD [0:02] } \\ {[\text { KG10] }} & \text { When the engine suddenly died. } & \text { MB [0,8] } & \text { MD [0:02] } \\ {[\text { KG13] }} & \text { The machine is turned difficult. } & \text { MB [0,7] } & \text { MD [0:04] } \\ {[\text { KG21] }} & \text { Engine running at idle is not stable. } & \text { MB [0,9] } & \text { MD [0:00] } \\ {[\text { KG26] }} & \text { Engine oil quickly reduced. } & \text { MB }[0,2] & \text { MD [0:00] }\end{array}$

MB combination value based on the above calculation for each symptom "Dirty Injection" as above is as follows:

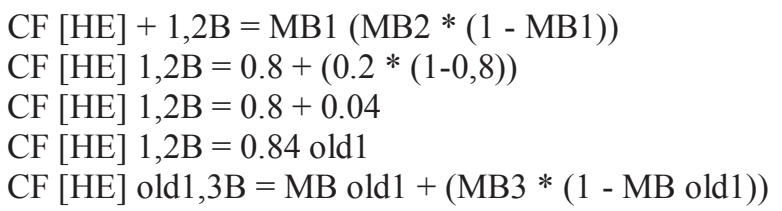




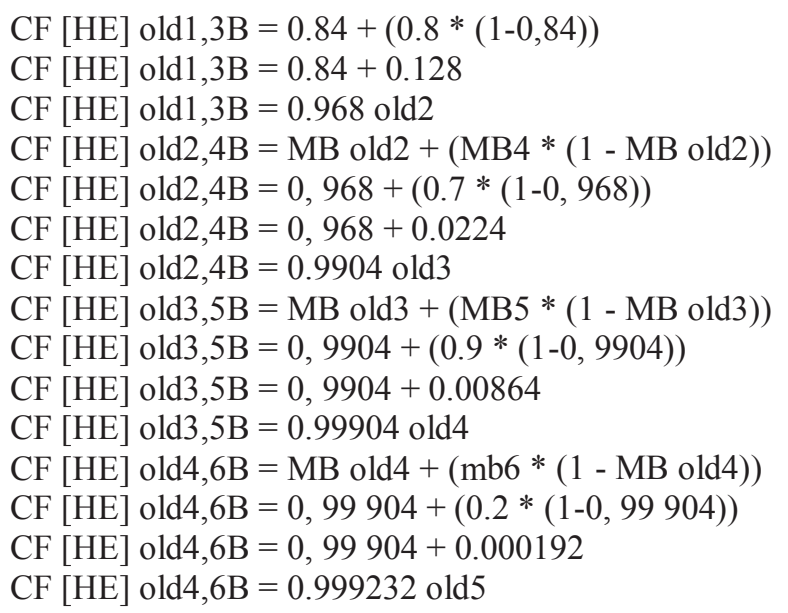

The combination of MD value based on the above calculation for each symptom "Dirty Injection" as above is as follows:

$\mathrm{CF}[\mathrm{HE}] 1,2 \mathrm{D}=\mathrm{MD} 1+(\mathrm{MD} 2 *(1-\mathrm{MD} 1))$

$\mathrm{CF}[\mathrm{HE}] 1,2 \mathrm{D}=0.04+(0.02 *(1-0,04))$

$\mathrm{CF}[\mathrm{HE}] 1,2 \mathrm{D}=0.04+0.0192$

$\mathrm{CF}[\mathrm{HE}] 1,2 \mathrm{D}=0.0592$ old 1

$\mathrm{CF}[\mathrm{HE}]$ old $1,3 \mathrm{D}=\mathrm{MD}$ old $1+(\mathrm{MD} 3 *(1-\mathrm{MD}$ old 1$))$

$\mathrm{CF}[\mathrm{HE}]$ old $1,3 \mathrm{D}=0,0592+(0.02 *(1-0,0592))$

$\mathrm{CF}[\mathrm{HE}]$ old $1,3 \mathrm{D}=0,0592+0.018816$

$\mathrm{CF}[\mathrm{HE}]$ old $1,3 \mathrm{D}=0.078016$ old 2

$\mathrm{CF}[\mathrm{HE}]$ old $2,4 \mathrm{D}=\mathrm{MD}$ old $2+(\mathrm{MD} 4 *(1-\mathrm{MD}$ old 2$))$

$\mathrm{CF}[\mathrm{HE}]$ old $2,4 \mathrm{D}=0,078016+(0.04 *(1-0,078$ 016) $)$

$\mathrm{CF}[\mathrm{HE}]$ old $2,4 \mathrm{D}=0,078016+0.03687936$

$\mathrm{CF}[\mathrm{HE}]$ old $2,4 \mathrm{D}=0.11489536$ old 3

$\mathrm{CF}[\mathrm{HE}]$ old $3,5 \mathrm{D}=\mathrm{MD}$ old $3+(\mathrm{MD} 5 *(1-\mathrm{MD}$ old 3$))$

$\mathrm{CF}[\mathrm{HE}]$ old $3,5 \mathrm{D}=0,11489536+(0.00 *(1-0,11,489,536))$

$\mathrm{CF}[\mathrm{HE}]$ old $3,5 \mathrm{D}=0,11,489,536+0$

$\mathrm{CF}[\mathrm{HE}]$ old $3,5 \mathrm{D}=0,11,489,536$ old 4

$\mathrm{CF}[\mathrm{HE}]$ old $4,6 \mathrm{D}=\mathrm{MD}$ old $4+(\mathrm{MD} 6 *(1-\mathrm{MD}$ old 4$))$

$\mathrm{CF}[\mathrm{HE}]$ old $4,6 \mathrm{D}=0,11489536+(0.00 *(1-0,11,489,536))$

$\mathrm{CF}[\mathrm{HE}]$ old $4,6 \mathrm{D}=0,11,489,536+0$

$\mathrm{CF}[\mathrm{HE}]$ old $4,6 \mathrm{D}=0,11,489,536$ old 5

Having obtained the MB and MD values then can be searched value of CF damage "Dirty Injection" as the following calculation:

$\mathrm{CF}=\mathrm{MB}$ (Certainty) - MD (Uncertainty)

$=.999232$ to 0.11489536

$=0.88433664$ or $88.43 \%$

It can be concluded that the damage was detected is Injection Dirty with confidence percentage is $88.43 \%$.

\subsection{System planning}

Designing the system to be built using modeling Unified Modeling Language (UML). Use case diagrams describe the interaction between the user and the system so that it can be understood more easily. Here is a use case diagram diagnosis expert system damage motorcycle injection. 


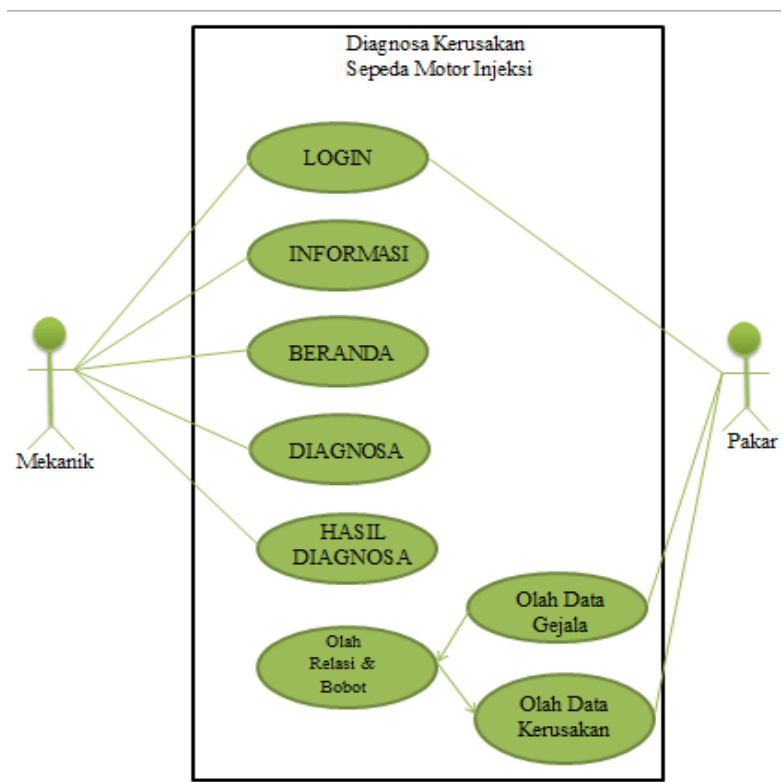

Fig. 2. Use Case Diagam Expert system

\section{Conclusion}

From the analysis, design, and implementation of this expert system making it obtained the following conclusions:

a. Expert systems using certainty factor method can be used as a guideline for the mechanic if you want to carry out repairs to the damage.

b. With the expert system can enable customers to increase knowledge and understanding of the various types of damage, the symptoms of damage and handling damage to the motorcycle injection.

c. The creation of an expert system application to detect damage to the motorcycle injection with Certainty Factor method is beneficial for mechanical because it can simplify and shorten the time to repair the damage.

d. The diagnosis had done olehpengunjung or mechanic can be accessed again by entering an email stored in the database.

\section{Reference}

[1] Anik Andriani, 2017, "Expert System Programming", Yogyakarta: Mediakom.

[2] Muhammad Arhami, 2017, "Basic Concepts of Expert Systems", Yogyakarta: Andi.

[3] Wahyu Wibowo Hartayo Marisa Dwi Midyanti, 2018, "Implementation of the Expert System Damage Motor Matic Diagnose Fuel Injection With Certainty Factor Method", Journal Untan Computer Systems, Vol. 06 (No. 03).

[4] Hengki Tamando Sihotang, 2014, "Expert System Diagnose Disease Cholesterol In Adolescents With methods Certainty Factor (CF) Web-based" logic of Penusa Journal, Volume 15 (No. 1), 1.

[5] Suryasari, Astrid Callista, Juwita Sari, 2018, "Application Design Customer Service at PT. Fluent Makmur Together ", Journal of Information Systems, Volume 4 (2).

[6] Dani Eko Hendrianto, 2014, "Making Website Library Information System Based On Junior High School 1 Donorojo Pacitan", Journal on Networking and Security, Volume 3 (\# 4).

[7] Early Destiani,2014, "Expert System Perancanagan amenorrhoea For Disease Diagnosis Method Using Expert System Development Life Cycle", Journal of Algorithms,Volume 2 (1)

[8] Aaron SujadiEni Suhaeni, 2016 "Expert System Diseases With Fever Symptoms Using Android-Based Mobile Devices", National Seminar on Information and Communications Technology, Volume 1 (4) 